\title{
Case Report: "ADHD Trainer": the mobile application that \\ enhances cognitive skills in ADHD patients [version 1; peer
}

\section{review: 1 approved with reservations]}

\author{
Gonzalo Ruiz-Manrique, Kazuhiro Tajima-Pozo, Francisco Montañes-Rada
}

Department of Psychiatry, Hospital Universitario Fundacion Alcorcon, Alcorcon, 28922, Spain

\begin{tabular}{l}
\hline V1 First published: 18 Nov 2014, 3:283 \\
https://doi.org/10.12688/f1000research.5689.1 \\
Second version: 07 May 2015, 3:283 \\
https://doi.org/10.12688/f1000research.5689.2 \\
Third version: 23 Jun 2015, 3:283 \\
https://doi.org/10.12688/f1000research.5689.3 \\
Fourth version: 10 Sep 2015, 3:283 \\
https://doi.org/10.12688/f1000research.5689.4 \\
Latest published: 26 Oct 2015, 3:283 \\
https://doi.org/10.12688/f1000research.5689.5
\end{tabular}

\section{Abstract}

We report the case of a 10 year old patient diagnosed with attention deficit hyperactivity disorder (ADHD) and comorbid video game addiction, who was treated with medication combined to a novel cognitive training method based on video games called TCT method. A great risk of developing video game or internet addiction has been reported in children, especially in children with ADHD. Despite this risk, we hypothesize that the good use of these new technologies might be useful to develop new methods of cognitive training. The cognitive areas in which a greater improvement was observed through the use of video games were the visuospatial working memory and fine motor skills. TCT method is a cognitive training method that enhances cognitive skills such as attention, working memory, processing speed, calculation ability, reasoning, and visuomotor coordination. The purpose of reviewing this case is to highlight that regular cognitive computerized training in ADHD patients can improve some of their cognitive symptoms and can help treating video game addition.

Keywords

ADHD; mobile app; TCT method; working memory

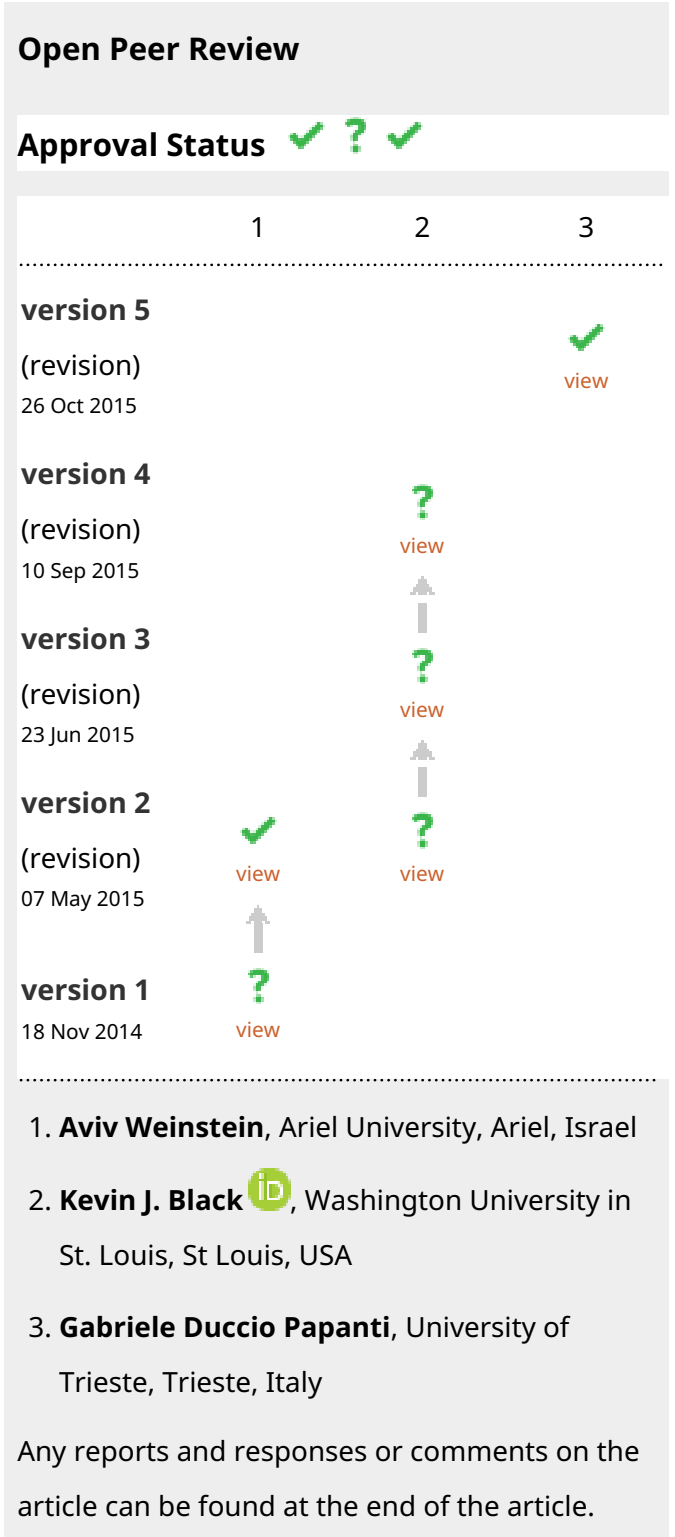


Corresponding author: Kazuhiro Tajima-Pozo (kazutajima@hotmail.com)

Competing interests: Dr. Kazuhiro Tajima-Pozo, participated in the development of "ADHD Trainer", and other mental health applications at TKT Brain Solutions, which is a Spanish startup, integrated by medical doctors and engineers, whose aim is to develop mental health applications.

Grant information: The author(s) declared that no grants were involved in supporting this work.

Copyright: (c) 2014 Ruiz-Manrique G et al. This is an open access article distributed under the terms of the Creative Commons Attribution License, which permits unrestricted use, distribution, and reproduction in any medium, provided the original work is properly cited.

How to cite this article: Ruiz-Manrique G, Tajima-Pozo K and Montañes-Rada F. Case Report: "ADHD Trainer": the mobile application that enhances cognitive skills in ADHD patients [version 1; peer review: 1 approved with reservations] F1000Research 2014, 3:283 https://doi.org/10.12688/f1000research.5689.1

First published: 18 Nov 2014, 3:283 https://doi.org/10.12688/f1000research.5689.1 


\section{Introduction}

Attention deficit hyperactivity disorder (ADHD) is the most commonly diagnosed neurodevelopmental disorder in childhood, which affects $3 \%$ to $7 \%$ of the population worldwide ${ }^{1}$. ADHD is characterized by distractibility, hyperactivity and impulsivity. The standard treatment for ADHD includes mainly medication, psychosocial and behavioral treatment, and cognitive training exercises.

Cognitive training exercises are especially useful when cognitive impairment is observed and when a regular and personalized cognitive training is performed ${ }^{2}$. Studies in participants with cognitive impairment have shown that regular and daily cognitive training can improve some of their cognitive symptoms ${ }^{3,4}$. In addition, recent studies have demonstrated that computerized working memory and executive function training programs lead to better results than ordinary cognitive training methods in children with $\mathrm{ADHD}^{5-7}$.

Children's use of electronic devices, Internet and video games, has noticeably increased in the last 10 years. Since the first case of Internet addiction was described in 1996 by Young ${ }^{6}$, several other pathologies have been proposed including pathological gambling and dependence ${ }^{7}$. Despite extensive research literature available, the prevalence and proper diagnostic criteria for pathological gaming are still debated among the scientific community ${ }^{8}$. Gaming addiction represents part of the postulated construct of Internet addiction, and is the most widely studied specific form of Internet addiction to date ${ }^{9}$. Prevalence estimates range from $2 \%{ }^{10}$ to $15 \%{ }^{11}$, depending on the respective socio-cultural context, sample, and assessment criteria utilized. A great risk of developing video game or Internet addiction has been reported in children, and especially in those with $\mathrm{ADHD}^{8}$. Despite this risk, we hypothesize that good use of these new technologies can be useful to develop new methods of cognitive training.

\section{Case report}

This case study involves a 10 year old child born in Madrid (Spain) who received treatment in a childhood psychiatry unit for 2 years due to behavioral disorders and ADHD. No other previous medical history was reported. His mother, aged 35, received psychological treatment for anxiety 3 years ago. His father, aged 36, works as an engineer and presented no relevant medical history. The patient was their only son. The parents described a great addiction to video games in the last year, a, referring 4 hours per day of video game playing, affecting his social interaction, and causing a lack of imaginative play and poor academic scores. Teachers at the school reported deterioration in his academic performance over the past year. At that time, the child was treated with methylphenidate $40 \mathrm{mg}$ per day. The patient's parents reported to the psychiatrist that the only significant change from the previous year was a major addiction to a war videogame.

To reduce the exposure to video games, we used a novel technique, cognitive stimulation with a mobile/tablet application designed specifically to treat ADHD, based on the method of Tajima Cognitive Method (TCT) cognitive training called "ADHD Trainer".

Behavioral and academic improvements were rated on the Conners Parent and Teacher Rating Scales (brief version) and Barkley School Situations Questionnaire.
ADHD diagnosis was made according to DSM V criteria ${ }^{9,10}$. Attention was rated with CPT Conners Continuous Performance Test.

A differential diagnosis between oppositional defiant disorder and ADHD disorder was considered, because most of the symptoms were observed at home, however not angry or irritable mood was observed.

The patient was treated with a combination of methylphenidate and a cognitive training method based in the TCT method. The patient received daily treatment with $40 \mathrm{mg}$ of methylphenidate, and at least 10 minutes of daily cognitive training with the "ADHD Trainer" app.

The TCT is a type of computer adaptive test (CAT), as it adapts to the individual's cognitive strengths and weaknesses, based on his own scores over time, as well as those of his peers. Users receive separate scores in different cognitive areas, including simple calculation, attention, perceptual reasoning, and visuomotor coordination (Figure 1). The goal of the daily training is to reach a pre-set individualized score in different cognitive domains, in order to complete a week of successful training.

During the first month of cognitive training therapy, the patient was only allowed to play with specific games based on the TCT Method, using the "ADHD Trainer" (Figure 2). The patient had to use the app every day at the same time, provided the other targets that were assigned in therapy, such as the progressive reduction in

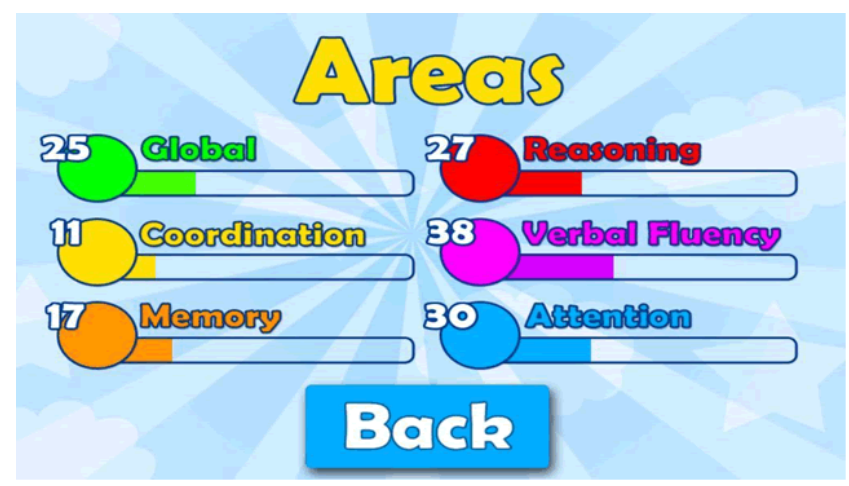

Figure 1. The cognitive areas treated with ADHD Trainer.

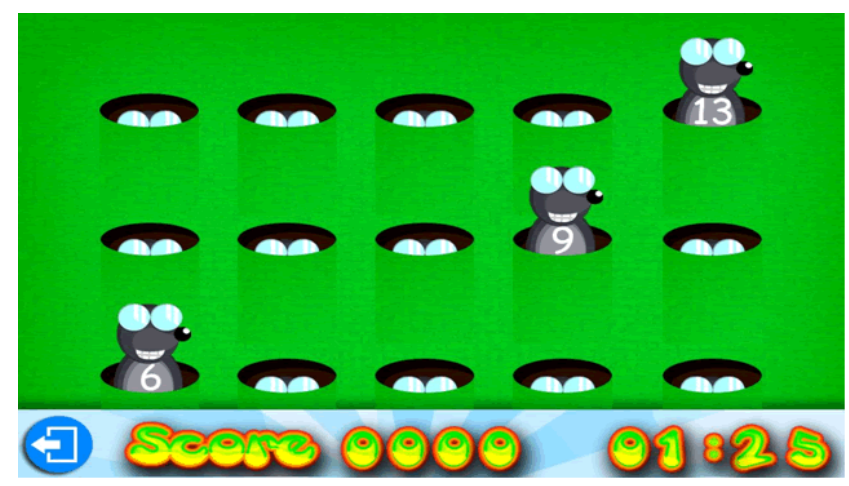

Figure 2. Capture of one of the games based in Trail Making Test. 
the number of hours to play other games and just being able to play with them once a week, were met. During the first month, he was allowed to play this game to a maximum range of 4 hours per day. No addiction to this videogame was observed during the first month. The average number of hours that the child played the video game was 1 hour a day. In the following months the objective was to play the game at least 10 minutes per day.

In less than two months the video games abuse was substantially reduced, limiting their use to weekends, and always for periods not exceeding 4 hours in total.

Behavioral and academic improvement was rated on the Conners Parent and Teacher Rating Scales and Barkley School Situations Questionnaire. The initial score of the Conners was 19 for the teachers and 20 for the parents, and after the cognitive training the scores were 15 for the teachers and 16 for the parents.

Both the school and the family reported a significant improvement in the patient after 6 months of TCT cognitive training, which included important improvements of both academic and behavioral outcomes.

\section{Discussion}

Most of the studies reported so far emphasize the potential addictive risk of new technologies and the influence they have on children's interpersonal development, by reducing the time children spend outside home and increasing the time they spend alone playing in front of a television or a computer screen ${ }^{12-14}$. It is also known that the new technologies may affect children's academic performance by reducing the number of hours that they dedicate to studying.

There are few studies which focus on the positive aspects of new technologies and the opportunities that they offer new ways of interaction between professionals and users as well as the development of new therapeutic methods, capable of reaching the young.

New technologies, in particular video games, can be used as therapeutic tools to train executive functions ${ }^{6,7}$. As they generate greater motivation in children and adolescents they will increase the frequency of performing cognitive tasks oriented to enhance executive functions, especially the working memory.

There are key advantages for children practicing the TCT Method relative to traditional cognitive training therapies which include:
1) Increased motivation in children for completing cognitive training therapy. This increase in motivation comes from: entertainment value (these games are designed to be similar to regular video games that children enjoy) and feedback on performances relative to own and peer scores (which improves children's sense of agency and self-efficacy, as demonstrated by documented research on motivation and learning $)^{11,12}$.

2) Ease of accessing the application. Children can play the games at any place or time, day and night.

\section{Conclusion}

ADHD patients are especially vulnerable to develop video gaming addition. ADHD patients often suffer from working memory and executive function dysfunctions, but we have observed that very few cognitive training techniques have been developed for ADHD patients in the last years. Poor completion rates of cognitive training in children with ADHD have been observed. We conclude that a daily cognitive computerized training in ADHD patients can improve some of their cognitive symptoms, and can help treating the video gaming addition.

\section{Consent}

Written informed consent to publish this report was obtained by the patient's parents.

Dr. Tajima takes responsibility for the integrity of the data and informed consent.

\section{Author contributions}

Dr. Gonzalo Ruiz wrote the manuscript, supervised by Dr. Kazuhiro Tajima-Pozo and Dr. Francisco Montañes-Rada. All authors agreed to the final content of the manuscript.

\section{Competing interests}

Dr. Kazuhiro Tajima-Pozo, participated in the development of "ADHD Trainer", and other mental health applications at TKT Brain Solutions, which is a Spanish startup, integrated by medical doctors and engineers, whose aim is to develop mental health applications.

\section{Grant information}

The author(s) declared that no grants were involved in supporting this work.
1. Weinstein $A$, Weizman $A$ : Emerging association between addictive gaming and attention-deficit/hyperactivity disorder. Curr Psychiatry Rep. 2012; 14(5): 590-7.

PubMed Abstract | Publisher Full Text

2. Martinussen R, Hayden J, Hogg-Johnson S, et al.: A meta-analysis of working memory impairments in children with attention-deficit/hyperactivity disorder.
J Am Acad Child Adolesc Psychiatry. 2005; 44(4): 377-84. PubMed Abstract | Publisher Full Text

3. Voelbel G, Ceceli A, Georgieva S, et al:: C-40Computerized Neuroplasticity Training Increases Processing Speed of Verbal Information: A Pilot Study of Adults with Traumatic Brain Injury. Arch Clin Neuropsychol. 2014; 29(6): 589. PubMed Abstract | Publisher Full Text 
4. Jungblut $\mathrm{M}$, Huber $\mathrm{W}$, Mais $\mathrm{C}$, et al.: Paving the way for speech: voice-training induced plasticity in chronic aphasia and apraxia of speech--three single cases. Neural Plast. 2014; 2014: 841982.

PubMed Abstract | Publisher Full Text | Free Full Text

5. Shaw R, Grayson A, Lewis V: Inhibition, ADHD, and computer games: the inhibitory performance of children with ADHD on computerized tasks and games. J Atten Disord. 2005; 8(4): 160-8.

PubMed Abstract | Publisher Full Text

6. Bioulac S, Arfi L, Bouvard MP: Attention deficit/hyperactivity disorder and video games: a comparative study of hyperactive and control children. Eur Psychiatry. 2008; 23(2): 134-41.

PubMed Abstract | Publisher Full Text

7. Lim CG, Lee TS, Guan C, et al:: Effectiveness of a brain-computer interface based programme for the treatment of ADHD: a pilot study. Psychopharmacol Bull. 2010; 43(1): 73-82.

PubMed Abstract

8. Walther B, Morgenstern M, Hanewinkel R: Co-occurrence of addictive behaviours: personality factors related to substance use, gambling and computer gaming. Eur Addict Res. 2012; 18(4): 167-74.

PubMed Abstract | Publisher Full Text

9. Keith Conners $\mathrm{C}: \mathrm{PhD}$ inventor; Conners 3rd Edition ${ }^{\mathrm{TM}}$ (Conners $3^{\mathrm{TM}}$ ). 2013. Reference Source

10. Dupaul GJ, Barkley RA: Situational Variability of Attention Problems: Psychometric Properties of the Revised Home and School Situation Questionnaires. J Clin Child Adolesc Psychol. 1992; 21(2): 178-188. Publisher Full Text

11. Dovis S, Van der Oord S, Wiers RW, et al.: Can motivation normalize working memory and task persistence in children with attention-deficit/hyperactivity disorder? The effects of money and computer-gaming. J Abnorm Child Psychol. 2012; 40(5): 669-81.

PubMed Abstract | Publisher Full Text | Free Full Text

12. Wilkinson N, Ang RP, Goh DH: Online video game therapy for mental health concerns: a review. Int J Soc Psychiatry. 2008; 54(4): 370-82.

PubMed Abstract | Publisher Full Text 


\section{Open Peer Review}

\section{Current Peer Review Status: ?}

\section{Version 1}

Reviewer Report 25 November 2014

https://doi.org/10.5256/f1000research.6082.r6739

(C) 2014 Weinstein A. This is an open access peer review report distributed under the terms of the Creative Commons Attribution License, which permits unrestricted use, distribution, and reproduction in any medium, provided the original work is properly cited.

\section{Aviv Weinstein}

Department of Behavioural Sciences, Ariel University, Ariel, Israel

This is an interesting case report on the usefulness of cognitive computer training for a child who is diagnosed with ADHD and concurrent videogame addiction. The rationale for the study, methods and findings are fine but I would like to make some additional comments.

First, the usefulness of treatment of ADHD and internet addiction by using methylphenidate was reported by Han D et al., 2009, please add it to the introduction.

Second, what evidence have you got that the child is not addicted to the educational game?

Third, 4 hours of play of a videogame post-treatment is still a lot, this should be mentioned as a limitation.

Fourth, why were the Conners ratings after treatment for parents and teachers lower compared with pre-treatment?

Fifth, the authors should be commended for the use of advanced computer games for treatment for ADHD. There are other tools for this purpose that are worthwhile mentioning such as ONTRAC (Mishra et al., 2013) and the game reported by Prins PJ et al., 2011.

Competing Interests: No competing interests were disclosed.

I confirm that I have read this submission and believe that I have an appropriate level of expertise to confirm that it is of an acceptable scientific standard, however I have significant reservations, as outlined above.

Author Response 10 Dec 2014

Kazuhiro Tajima-Pozo, Hospital Universitario Fundacion Alcorcon, Alcorcon, Spain 
We have included the following new references and made the changes according to the reviewer comments.

Mishra J, Merzenich MM, Sagar R. Accessible online neuroplasticity-targeted training for children with ADHD. Child Adolesc Psychiatry Ment Health. 2013 Nov 14;7(1):38

Prins PJ, Dovis S, Ponsioen A, ten Brink E, van der Oord S. Does computerized working memory training with game elements enhance motivation and training efficacy in children with ADHD? Cyberpsychol Behav Soc Netw. 2011 Mar;14(3):115-22.

Han DH1, Lee YS, Na C, Ahn JY, Chung US, Daniels MA, Haws CA, Renshaw PF. The effect of methylphenidate on Internet video game play in children with attentiondeficit/hyperactivity disorder.

Competing Interests: No competing interests were disclosed.

Author Response 13 Apr 2015

Kazuhiro Tajima-Pozo, Hospital Universitario Fundacion Alcorcon, Alcorcon, Spain

We have included the following new references and made the changes according to the reviewer comments.

Mishra J, Merzenich MM, Sagar R. Accessible online neuroplasticity-targeted training for children with ADHD. Child Adolesc Psychiatry Ment Health. 2013 Nov 14;7(1):38

Prins PJ, Dovis S, Ponsioen A, ten Brink E, van der Oord S. Does computerized working memory training with game elements enhance motivation and training efficacy in children with ADHD? Cyberpsychol Behav Soc Netw. 2011 Mar;14(3):115-22.

Han DH1, Lee YS, Na C, Ahn JY, Chung US, Daniels MA, Haws CA, Renshaw PF. The effect of methylphenidate on Internet video game play in children with attentiondeficit/hyperactivity disorder.

Competing Interests: Dr. Kazuhiro Tajima-Pozo, participated in the development of "ADHD Trainer", and other mental health applications at TKT Brain Solutions, which is a Spanish startup, integrated by medical doctors and engineers, whose aim is to develop mental health applications.

\section{Comments on this article}

\section{Version 1}




\section{Author Response 13 Apr 2015}

Kazuhiro Tajima-Pozo, Hospital Universitario Fundacion Alcorcon, Alcorcon, Spain

Thanks for your comments Mr Black! best regards

Competing Interests: No competing interests were disclosed.

Reader Comment ( F1000Research Advisory Board Member ) 20 Nov 2014

Kevin J Black, Department of Psychiatry, Washington University in St Louis, USA

This is a trivial comment, just FYI, but the phrase "integrated by medical doctors and engineers" in the Competing Interests section sounds great in Spanish, but would be better rendered in English as "made up of physicians and engineers."

Competing Interests: none

The benefits of publishing with F1000Research:

- Your article is published within days, with no editorial bias

- You can publish traditional articles, null/negative results, case reports, data notes and more

- The peer review process is transparent and collaborative

- Your article is indexed in PubMed after passing peer review

- Dedicated customer support at every stage

For pre-submission enquiries, contact research@f1000.com 